indistintamente indígenas e sertanejos/caboclos, relevadas as nuances diferenciais, que aqui não vem ao caso abordar, destaca-se a experiência da migração. Aliás, convém frisar que, desde a chegada dos primeiros colonizadores, o deslocamento forçado tornou-se fenômeno muito conhecido dos indígenas brasileiros. $\mathrm{O}$ foco deste trabalh $\mathrm{O}^{2}$ é acompanhar a trajetória do deslocamento de duas comunidades indígenas - os tuxá e pankararú - que habitam atualmente a região do Médio São Francisco, em períodos não muitos recuados.

Ano/Edição Ano XIV, no39, jan-abril/2001. São Paulo

\begin{tabular}{l|l}
\hline Título & $\begin{array}{l}\text { Fronteiras de tradição cultural Guarani Mbya e a presença do } \\
\text { Jurua (civilizado) nas Reservas Indígenas }\end{array}$ \\
\cline { 2 - 2 } Autor/es & Marília G. Ghizzi Godoy \\
Resumo & Relato \\
Ano/Edição & Ano XVII, no 48, jan-abril/2004 \\
\hline
\end{tabular}

\title{
INDOCUMENTAÇÃO
}

\author{
Título \\ Tá legal? Tudo em ordem? Tudo sob controle? \\ Autor/es \\ Resumo \\ Heinz Dieter Heidemann \\ Ano/Edição \\ Editorial \\ Ano XI, no 30, jan-abril/1998. São Paulo-SP
}

$\begin{array}{ll}\text { Título } & \begin{array}{l}\text { Migraçães internacionais não-documentadas: uma tendência } \\ \text { global crescente }\end{array} \\ \text { Autor/es } & \text { Hugo Graeme } \\ \text { Resumo } & \text { A Globalização é um dos fenômenos mais difundidos do } \\ \text { dos anos noventa e associado a CIC. fluxos financeiros, bens } \\ \text { e informações cruzam fronteiras nacionais em volumes } \\ \text { nunca antes verificados. Globalização e redução massiva dos } \\ \text { custos reais de viagem têm mostrado também um aumento } \\ \text { na escala c complexidade no movimento de pessoas entre } \\ \text { nações. Entretanto, as barreiras oficiais erguidas por Estados } \\ \text { Nações para o influxo de pessoas têm sido mais resistentes } \\ \text { ao processo da globalização do que as barreiras aos fluxos } \\ \text { de informações. movimentos financeiros e mercadorias. } \\ \text { Contudo, as desigualdades, diferenças e complenlentaridades } \\ \text { internacionais que propiciaram os outros fluxos são } \\ \text { impingidos de forma igualmente forte sobre as pessoas. }\end{array}$


Diante das barreiras impostas à entrada nos países. as migrações internacionais, aquelas que acontecem à margem dos sistemas oficiais de controle, crescem exponencialmente. De fato. pode parecer que exista pelo menos a mesma quantidade de migrantes internacionais ilegais quanto migrantes oficialmente reconhecidos. Entretanto, quase toda a pesquisa e literatura disponíveis sobre padrões, causas e consequências das migrações internacionais dedicam-se à consideração dos migrantes legalmente documentados; fato que não surpreende dadas as dificuldades inerentes em medir as migrações nào-documcntadas, sem mencionar aqui as dificuldades em estudá-las detalhadamente.

Ano/Edição Ano XI, no 30, jan-abril/1998. São Paulo-SP

Título Autor/es Resumo

\section{A legitimidade da condição clandestina}

\section{Teresa Sales}

Quando estudei a migração de "corumbas" (pequenos produtores agrícolas da região do Agreste de Pernambuco que na época do corte da cana se deslocam temporariamente à Zona da Mata), o principal critério para classificar os trabalhadores rurais naquela região canavieira do Nordeste era sua condição de "fichados" ou "clandestinos" (Suarez, 1977). Usei na verdade uma autonomearão pré-existente na região desde o início dos anos 60 (anos que representaram um importante marco dos movimentos sociais rurais). quando os trabalhadores daquela região que conseguiram legalizar sua situação trabalhista passaram a se autonomear de trabalhadores "fichados". A situação antinómica seria a dos "clandestinos", ou seja, aqueles que estavam fora dos direitos por não terem conseguido ainda regularizar sua situação trabalhista. Onde não houve esse marco de lutas pelos direitos. como no caso da região canavieira de São Paulo, os mesmos tipos de trabalhadores eram e são ainda nomeados de "boiasfrias", O sentido ali atribuído ao "clandestino" em oposição ao "fichado", é a condição do trabalhador rural de estar excluído dos direitos trabalhistas; ou seja: é clandestino não por estar em uma situação ilegal. mas por estar excluído da situação de legalidade. São exemplos históricos que podem ser úteis para alguém refletir sobre a situação de clandestinidade dos atuais imigrantes brasileiros, tanto em seu processo migratório, quanto em seu cotidiano enquanto imigrantes ilegais ou indocumentados em um país estrangeiro. Vou explorar a hipótese de que a sua situação se assemelha em vários 
aspectos à situação dos nossos trabalhadores "clandestinos" a que me referi anteriormente, ou seja, são clandestinos não porque estejam fora da lei, no sentido de estarem contrários a ela (tal como o exemplo dos partidos clandestinos), mas sim porque estão excluídos de uma lei que os deveria beneficiar. Por outro lado, os imigrantes indocumentados desfrutam de uma condição legítima na sociedade americana que os leva a não se sentirem clandestinos (contrários às leis vigentes), mas sim excluídos dos direitos a que deveriam fazer jus. Essa legitimidade da condição de imigrante indocumentado é lastreada, por um lado, nos pressupostos da nação americana (nação de imigrantes); e por outro, nas relações étnicas do grupo, que se vê detentor de direitos lá dos quais são preteridos no Brasil, sendo a Igreja (que é o principal vínculo de sociabilidade do imigrante brasileiro nos Estados Unidos) a principal instituição que dá suporte à legitimidade da condição clandestina do imigrante brasileiro naquele país. As páginas que seguem constituem uma reflexão sobre a questão da clandestinidade dos imigrantes brasileiros, a partir de dados de minhas entrevistas realizadas entre setembro de 1995 e janeiro de 1996 na região da Grande Boston, estado de Massachusetts, USA.

Ano/Edição Ano XI, no 30, jan-abril/1998. São Paulo-SP

Título

Autor/es

Resumo

\section{"IIRIRA 96" - fechando o cerco aos clandestinos nos EUA}

\section{Joyce Anne Rodrigues Monteiro}

Ao pensarmos na migração internacional, poucos países nos chamam a atenção como os Estados Unidos, o principal país de destino da maior parte dos migrantes espalhados pelo mundo e recentemente também de imigrantes brasileiros. Ao longo dos anos, os Estados Unidos têm se destacado não só por ser considerado como uma nação de imigrantes, como pelo fato de que, desde 1965, esse país tem implantado leis de imigração liberais, que privilegiam o critério de reunir famílias separadas pela migração. No entanto. o grande número de imigrantes que têm chegado nos últimos anos nos Estados Unidos tem gerado uma série de debates e despertado muitas polêmicas sobre a utilidade c o papel desses imigrantes. principalmente os clandestinos (ou ilegais), na sociedade americana. A maioria da população branca dominante, em especial, tem apresentado uma certa resistência em aceitar a nova população constituída por latinos e asiáticos. Como 
resultado, pressões para um aumento no controle de quem pode ou não entrar no pais têm sido cada vez maiores. Assim, o último passo dado para restringir o ingresso desses imigrantes envolve a sua política migratória, ou seja, os critérios estabelecidos pela lei americana para controlar esse fluxo, o que se fez sentir diretamente na mais recente lei de imigração. mais conhecida como IIRIRA 96 . O objetivo desse artigo é esclarecer como essa última lei atinge os imigrantes, $\mathrm{cm}$ especial os ilegais, explicando as suas principais cláusulas. Antes disso, no entanto. será feito um breve Resumo das políticas migratórias nos Estados Unidos para compreendermos melhor como essa lei trouxe transformações fundamentais para a política migratória americana dos últimos trinta anos.

Ano/Edição Ano XI, no 30, jan-abril/1998. São Paulo-SP

\section{Título}

Uma exploração muito particular: o caso da migração mexicana para os EUA

Autor/es

\section{John Gledhill}

Resumo

No mês de abril do ano de 1997 entrou em vigor nos Estados Unidos uma lei que regulamenta a imigração ilegal explicitando a responsabilidade dos imigrantes, juntamente com a lei de reforma da assistência pública, pena de morte e antiterrorismo. A combinação de tais medidas, supostamente contrárias ao "terrorismo", num conjunto de medidas que pretende reformar leis migratórias, nos oferece uma visão preliminar do clima ideológico que já tem consequências diretas na vida dos trabalhadores mexicanos nos Estados Unidos. Cabe ressaltar ainda que também o Congresso Americano não tem deixado de relacionar a questão da migração "indocumentada" à questão do narcotráfico. A proposta deste artigo é relacionar os acontecimentos recentes com uma história mais ampla da migração de trabalhadores mexicanos para os Estados Unidos, com o objetivo de demonstrar que os mexicanos tendem a enfrentar uma dupla situação de desvantagem nos seus intentos de ganhar a vida no Norte, Por um lado, seus esforços económicos sempre têm fortalecido o país vizinho, e os governos mexicanos têm procurado fortalecer uma relação de conformidade às demandas das administrações estadunidenses no que se refere à política migratória. Essa questão está bem explícita no Tratado de Livre Comércio de 1994, o qual permite a liberdade de movimento do capital, 
porém a nega aos trabalhadores, assegurando, assim, que a mão-de-obra mexicana seja barata e sofra desvantagens no que se refere aos direitos trabalhistas nos dois lados da fronteira. Por outro lado, continuam experimentando uma situação neocolonial, na qual a sociedade norte-americana conserva o direito de recusar os migrantes como pessoas, negando-lhes os seus direitos mínimos, continuando, porém, a usufruir o direito de explorar a sua força de trabalho.

Ano/Edição Ano XI, no 30, jan-abril/1998. São Paulo-SP

$\begin{array}{ll}\text { Título } & \text { Um flagrante na clandestinidade } \\ \text { Autor/es } & \text { Sidnei Marco Dornelas } \\ \text { Resumo } & \text { Na noite do dia } 24 \text { de julho de 1997, o "Jornal Nacional" da } \\ \text { Rede Globo noticiava na sua primeira chamada: "Flagrante: } & \text { bolivianos viram escravos em São Paulo". Depois, na sua } \\ \text { primeira reportagem o apresentador iniciava repetindo a } \\ \text { manchete em tom bombástico: "Trabalho escravo na maior } \\ \text { cidade do País". Era a notícia do desmantelamento de uma } \\ \text { oficina de costura funcionando ilegalmente na Zona Leste } \\ \text { da cidade de São Paulo, em que trabalhavam 23 imigrantes } \\ \text { bolivianos clandestinos, sob condições de superexploração. Tal } \\ \text { destaque chama a atenção. pois são raras as oportunidades } \\ \text { em que a grande imprensa, sobretudo a televisiva. traz } \\ \text { notícias sobre a clandestinidade de estrangeiros no País. Trata- } \\ \text { se de um fenómeno relativamente desconhecido da sociedade } \\ \text { brasileira e que. quando surge, aparece como uma ocorrência } \\ \text { policial, como denúncia de 'escravidão 'como um escândalo } \\ \text { diante da opinião pública. Manchetes como essas trazem todo } \\ \text { tipo de associações negativas à presença de imigrantes ilegais } \\ \text { em nosso País. Para o grande público ocorre a massificação } \\ \text { de associações como "escravidão", "clandestinidade", } \\ \text { (bolivianos)/"crime, (ilegalidade). Em torno dessa ação da } \\ \text { grande imprensa sobre um fenómeno relativamente ignorado } \\ \text { pela sociedade brasileira, a clandestinidade de imigrantes } \\ \text { ilegais. e a partir da recuperação desse caso especifico, } \\ \text { tentaremos esboçar algumas reflexões. Tentaremos também } \\ \text { visualizar a situação peculiar em que se encontra a Pastoral } \\ \text { dos Migrantes diante dessa realidade. } \\ \text { Ano XI, no 30, jan-abril/1998. São Paulo-SP }\end{array}$




\begin{tabular}{ll}
$\begin{array}{l}\text { Título } \\
\text { Autor/es } \\
\text { Resumo } \\
\text { Ano/Edição }\end{array}$ & $\begin{array}{l}\text { Migrantes ilegais: a vida e a lei (Relato de experiência) } \\
\text { Relato de experiência } \\
\text { Ano XI, no 30, jan-abril/1998. São Paulo-SP }\end{array}$ \\
\hline Título & $\begin{array}{l}\text { Clandestinidade e intolerância - caso dos bolivianos em São } \\
\text { Paulo }\end{array}$ \\
\hline Autor/es & $\begin{array}{l}\text { Sidney Antonio da Silva } \\
\text { Eesumo portanto, proposta deste trabalho analisar as várias faces da } \\
\text { clandestinidade vivida por um grupo de imigrantes bolivianos } \\
\text { em São Paulo, mostrando que o principal desafio que esses } \\
\text { imigrantes podem enfrentar na cidade não é a questão jurídica } \\
\text { da clandestinidade, condição esta que não se constitui em um } \\
\text { problema maior para o seu dia-a-dia, mas as várias acusaçães } \\
\text { preconceituosas, as quais revelam como as alteridades } \\
\text { enquanto negatividade são construídas e manipuladas no } \\
\text { mundo contemporâneo. }\end{array}$ \\
Ano/Edição & \begin{tabular}{l} 
Ano XI, no 30, jan-abril/1998. São Paulo-SP \\
\hline
\end{tabular}
\end{tabular}

\section{LITERATURA}

\begin{tabular}{|c|c|}
\hline Título & Migrante sazonal - “ave ferida” (Poema) \\
\hline Autor/es & Alfredo Jose' Gonçalves \\
\hline Resumo & Poema \\
\hline Ano/Edição & Ano I, no 1, maio-ago/1988. São Paulo \\
\hline Título & Conversa ao pé de um ponto de ônibus (Crônica) \\
\hline Autor/es & Dirceu Cutti \\
\hline Resumo & Crônica \\
\hline Ano/Edição & Ano I, no 2, set-dez/1988. São Paulo \\
\hline Título & Buscar o amanhã... um amanhã novo! (Poema) \\
\hline Autor/es & Alfredo José Gonçalves \\
\hline Resumo & Poema \\
\hline Ano/Edição & Ano I, no 3, jan-abril/1989. São Paulo \\
\hline Título & Forjando resistência (Poema) \\
\hline Autor/es & Editorial de Travessia \\
\hline Resumo & Poema \\
\hline Ano/Edição & Ano I, no 1, set-dez/1988. São Paulo \\
\hline
\end{tabular}

